Gut, 1985, 26, 1183-1188

\title{
Campylobacter pyloridis in peptic ulcer disease: microbiology, pathology, and scanning electron microscopy
}

\author{
A B PRICE, J LEVI, JEAN M DOLBY, P L DUNSCOMBE, A SMITH, \\ J CLARK, AND MARY L STEPHENSON
}

From the Departments of Histopathology and Gastroenterology, Northwick Park Hospital and Division of Communicable Diseases, Clinical Research Centre, Harrow, Middlesex

SUMmARY After the recent successful isolation of spiral organisms from the stomach this paper presents the bacteriological and pathological correlation of gastric antral biopsies from 51 patients endoscopied for upper gastrointestinal symptoms. Campylobacter pyloridis was cultured from 29 patients and seen by either silver staining of the biopsy or scanning electron microscopy in an additional three. The organism was cultured from 23 of the $33(69 \%)$ patients with peptic ulcer disease and from within this group $17(80 \%)$ of the 21 patients with duodenal ulceration. It was cultured only once from the 12 normal biopsies in the series but from 27 of the $38(71 \%)$ biopsies showing gastritis. $C$ pyloridis was also cultured from five out of seven of the 14 endoscopically normal patients, who despite this had biopsy evidence of gastritis. It was the sole organism cultured from $65 \%$ of the positive biopsies and scanning electron microscopy invariably revealed it deep to the surface mucus layer. $C$ pyloridis persisted in the three patients with duodenal ulcers after treatment and healing. The findings support the hypothesis that $C$ pyloridis is aetiologically related to gastritis and peptic ulceration though its precise role still remains to be defined.

The presence of spiral bacteria on gastric mucosa has been noted by histopathologists for many years. ${ }^{1}$ Fresh impetus to these observations and to the search for the aetiology of peptic ulcer disease has been given by the culture of these organisms and the demonstration of their association with gastritis and duodenal ulcer. ${ }^{2-4}$ Other communications ${ }^{5-7}$ have upheld these initial findings. The provisional name of Campylobacter pyloridis has been assigned to the new organism. ${ }^{3} 8$

This paper presents a prospective study on a series of patients with peptic ulcer disease, designed to look at the incidence of this new organism in the stomach and to try and shed light on whether it is a pathogen or not.

\section{Methods}

\section{PATIENTS AND ENDOSCOPY}

The study comprised 51 patients presenting to the

Address for correspondence: Dr Ashley B Price, Department of Histopathology, Northwick Park Hospital, Watford Road, Harrow, Middlesex HA 1 $3 \mathrm{UJ}$.

Received for publication 4 January 1985 gastroenterology clinic at Northwick Park Hospital who were divided into the following groups: acute duodenal ulcer 21 , healed duodenal ulcer two, chronic gastric ulcer seven, healed gastric ulcer three, gastritis two and pernicious anaemia two. There was also a group of 14 patients with dyspeptic symptoms but without endoscopic abnormality.

At endoscopy three mucosal biopsies were taken from each patient from within $5 \mathrm{~cm}$ of the pylorus. These were submitted in separate containers, one for bacteriological culture, and one each for examination by light and scanning electron microscopy (SEM). The 51 patients provided 55 biopsy samples as four patients had follow up biopsies. The diagnoses were coded and known only to the endoscopist (AS) until the end of the study.

\section{HISTOPATHOLOGY AND SCANNING ELECTRON} MICROSCOPY

The biopsies for light microscopy were fixed in $10 \%$ formalin, routinely processed to paraffin and $3 \mu \mathrm{m}$ sections cut. Sections from all 55 biopsies were stained with haematoxylin and eosin and by the 
Warthin-Starry technique. The classification of gastritis was that of Whitehead ${ }^{9}$ into chronic superficial and chronic atrophic gastritis of mild, moderate or severe degree. The pattern of inflammation was further categorised as 'active' or 'quiescent'. 'Active' required the presence of polymorphs infiltrating mucosal epithelial cells and accompanying degenerative changes: polymorphs were absent in those classed 'quiescent'. ${ }^{10}$ Glutaraldehyde and osmium tetroxide fixed biopsies for SEM were dehydrated, coated with gold and viewed with a Phillips SEM 500 microscope.

\section{MICROBIOLOGY}

The antral biopsies, received within 10 minutes, were homogenised in broth anaerobically and aliquots of 10 -fold dilutions plated on selective and non-selective media. Plates were incubated under four sets of conditions: anaerobically at $37^{\circ} \mathrm{C}$ up to four days, (prereduced blood agar and selective media for bacteriodes and veillonella), aerobically (MacConkey agar) or in a candle jar at $37^{\circ} \mathrm{C}$ up to two days (blood agar) and in the campylobacter gas mixture containing about $5 \%$ oxygen, $10 \%$ carbon dioxide, nitrogen and hydrogen at $37^{\circ} \mathrm{C}$ for up to seven days (Skirrow's selective agar for $C$ jejuni and blood agar).

Organisms were counted and representative colonies identified morphologically for comparison with SEM findings. A few routine biochemical tests were additionally done on campylobacter like organisms and slides prepared for immunofluorescence with the 'common' antibody to Campylobacter spp including $C$ pyloridis. ${ }^{11}$

Checks on the endoscopes, treated with an antiseptic solution of chlorhexidine and cetrimide (Savlodil, ICI) and washed between examinations showed that campylobacter like organisms were not being transferred.

\section{Results}

The culture results have been correlated with patient group (Table 1) and with histological classification (Table 2).

\section{MICROBIOLOGY}

$C$ pyloridis was isolated from 29 of the 51 patients. This included 17 of the $21(81 \%)$ patients with duodenal ulceration.

All biopsy tissue was cultured for campylobacter like organisms and a complete bacterial analysis was performed on 48 biopsies. In $10(20 \%) C$ pyloridis and other organisms (streptococci, enterobacteriaceae, diptheroids, and occasionally anaerobic bacteria) were found. In 19 others $(40 \%) C$ pyloridis
Table 1 Relation between patient group and growth of C pyloridis

\begin{tabular}{lcc}
\hline Endoscopic diagnosis & $\begin{array}{l}\text { Patients } \\
\text { (no) }\end{array}$ & Culture positive \\
\hline Duodenal ulcer & $(21)$ & $17(81 \%)$ \\
Healed duodenal ulcer & $(2)$ & 1 \\
Gastric ulcer & $(7)$ & $4(57 \%)$ \\
Healed gastric ulcer & $(3)$ & 1 \\
Gastritis only & $(2)$ & 1 \\
Pernicious anaemia & $(2)$ & 0 \\
Normal endoscopy & $(14)$ & $5(36 \%)$ \\
Total & 51 & 29 \\
\hline
\end{tabular}

was the sole organism. These represent 11 patients with duodenal ulceration, four with normal endoscopy and four from among the other groups. In nine further biopsies (19\%) other organisms but not $C$ pyloridis were cultured and the remaining 10 were sterile. Thus of the fully analysed biopsies yielding any growth, $C$ pyloridis was present in pure culture in $65 \%$. Numbers ranged from $10^{2}-10^{5} / 5 \mathrm{mg}$ piece of tissue.

The organism was similar to that reported by Marshall and colleagues ${ }^{3}$ being $3 \mu \mathrm{m}$ in length with three to four unipolar, sheathed flagellae. Organisms were haemolytic and failed to grow at $43^{\circ} \mathrm{C}$ and growth was often better on blood agar than on selective agar containing vancomycin, trimethoprim and polymyxin B. On subculture they would grow well in a candle jar. All but three of the 24 isolates tested fluoresced with the antibody to the common campylobacter antigen. ${ }^{11}$

\section{HISTOPATHOLOGY}

Inspection of the histological correlation (Table 2) shows that $C$ pyloridis was isolated from 19 of 25 (76\%) biopsies with chronic superficial gastritis and from eight of $13(62 \%)$ with chronic atrophic gastritis. 'Activity' of inflammation (see methods) was irrelevant, $C$ pyloridis being found in $68 \%$ of biopsies considered 'actively' inflamed and in $62 \%$ classed 'quiescent'.

All of the biopsies were examined by the WarthinStarry stain. The organism was recognised in biopsies from 25 patients, 23 of whom were also culture positive (Fig. 1). One of the two patients over which there was disagreement had a duodenal ulcer and organisms were also seen at SEM (see below). The other patient had a healed gastric ulcer.

Organisms could not be seen in the biopsies from 21 patients, three of whose biopsies yielded positive cultures. These three comprised two patients with gastric ulcers and one patient endoscopically normal but with biopsy proven gastritis (Table 2).

The interpretation of the Warthin-Starry stain was 
Table 2 Correlation of patient group, with histopathology and culture of $\mathrm{C}$ pyloridis

\begin{tabular}{|c|c|c|c|c|c|c|c|c|c|}
\hline \multirow{2}{*}{\multicolumn{2}{|c|}{ Histopathology }} & \multicolumn{8}{|c|}{ Patient groups } \\
\hline & & $D U$ & $H D U$ & $G U$ & $H G U$ & Gi. & $P A$ & $N$ & Total \\
\hline \multicolumn{2}{|l|}{ Normal } & 1 & & $3(1)$ & & & 1 & 7 & $12(1)$ \\
\hline $\begin{array}{l}\text { Chronic } \\
\text { superficial } \\
\text { gastritis }\end{array}$ & $\begin{array}{l}\text { mild } \\
\text { mod. } \\
\text { severe }\end{array}$ & $\begin{array}{l}8(6) \\
3(3) \\
3(3)\end{array}$ & $1(0)$ & $\begin{array}{l}1(1) \\
1(1)\end{array}$ & $1(1)$ & 1 & 1 & $5(4)$ & $\begin{array}{c}16(10) \\
5(5) \\
4(4)\end{array}$ \\
\hline $\begin{array}{l}\text { Chronic } \\
\text { atrophic } \\
\text { gastritis }\end{array}$ & $\begin{array}{l}\text { mild } \\
\text { mod. } \\
\text { severe }\end{array}$ & $\begin{array}{l}1(1) \\
5(4)\end{array}$ & $1(1)$ & $1(1)$ & 1 & & & $\begin{array}{l}1(1) \\
1\end{array}$ & $\begin{array}{l}4(3) \\
6(4) \\
3(1)\end{array}$ \\
\hline \multicolumn{2}{|l|}{ Inadequate } & & & & & $1(1)$ & & & $1(1)$ \\
\hline \multicolumn{2}{|l|}{ Total } & $21(17)$ & $2(1)$ & $7(4)$ & $3(1)$ & $2(1)$ & 2 & $14(5)$ & $51(29)$ \\
\hline
\end{tabular}

The figures in parentheses are those from whom $C$ pyloridis cultured. $\mathrm{DU}=$ duodenal ulcer; $\mathrm{HDU}=$ healed duodenal ulcer; $\mathrm{GU}=\mathrm{gastric}$ ulcer; HGU =healed gastric ulcer; $\mathrm{Gi}$. = gastritis; $\mathrm{PA}=$ pernicious anaemia; $\mathrm{N}=$ normal endoscopy.

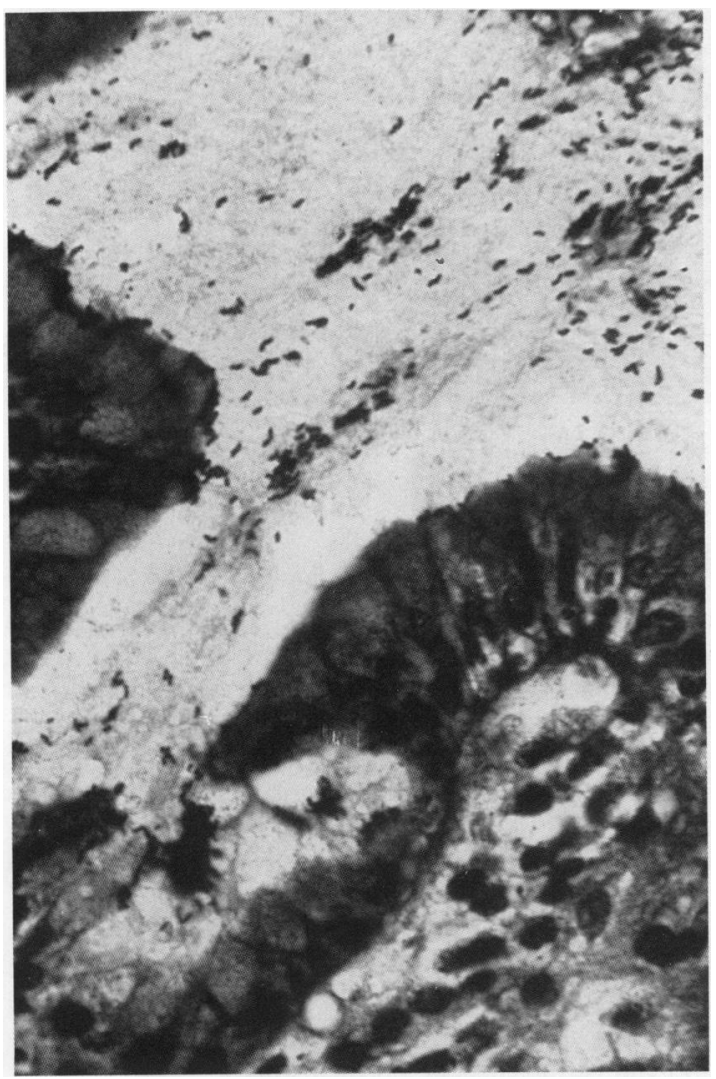

Fig. 1 Gastric mucosa showing $\mathrm{C}$ pyloridis adherent to the surface epithelium and free above it. Only some are sectioned in planes demonstrating their characteristic shape, a limitation of histological identification. Warthin-Starry stain $\times 1000$. equivocal in four cases and one biopsy was inadequate. The organism was never seen in a normal biopsy. Table 2 also shows that only one patient with a duodenal ulcer had a normal antral biopsy and $C$ pyloridis was absent. Furthermore it is clear that the endoscopically normal patients from whom $C$ pyloridis was grown did have histological evidence of gastritis.

\section{SCANNING ELECTRON MICROSCOPY}

Forty seven of the biopsies submitted proved suitable for SEM. C pyloridis was only seen in close relation to the mucosal surface (Fig. 2), always below the mucus layer. In 26 , mucus totally covered the biopsy and $C$ pyloridis was not seen. In the remaining 21 at least some mucosa was visible. From nine of these $C$ pyloridis was both seen and cultured and from nine it was neither cultured nor seen. There were two positive sightings by SEM alone, both in tissue from patients with duodenal ulcers. In only one case were organisms cultured and not seen at SEM.

In eight biopsies, all from patients with peptic ulcers, large $(10 \mathrm{um})$ cigar shaped organisms were seen on the surface of the mucus but these could not be matched against any one of the organisms cultured (Fig. 3). From all but one of these $C$ pyloridis was also grown.

\section{FOLLOW UP DATA}

In four patients a second biopsy was taken after one month and after treatment with $\mathrm{H} 2$ receptor antagonists. In three a duodenal ulcer had healed during that period yet in all $C$ pyloridis persisted. The fourth patient had evidence of a healed duodenal ulcer on both occasions and both times $C$ pyloridis was absent. There was full agreement on the repeat biopsies between culture and silver stains. 


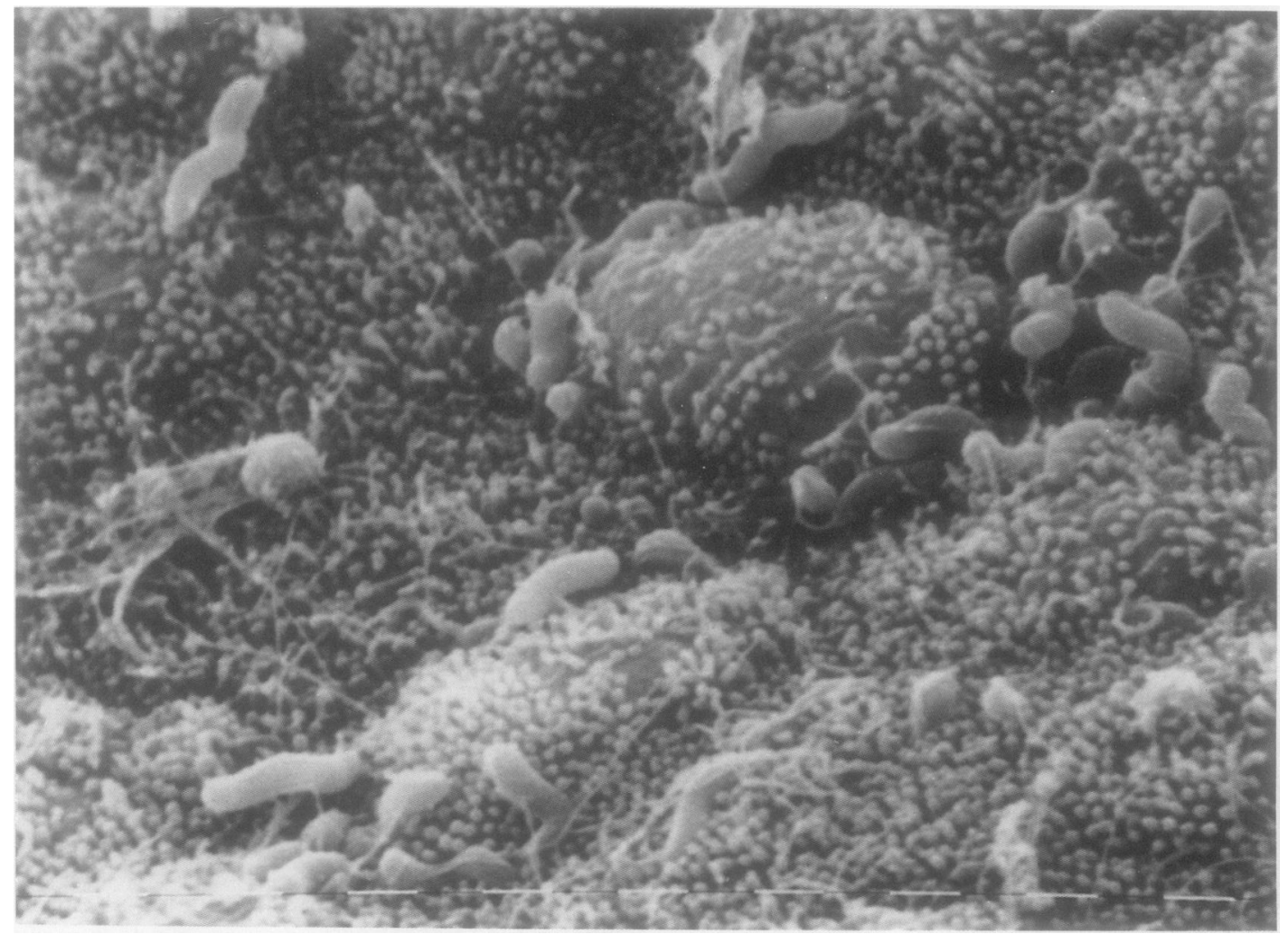

Fig. 2 C pyloridis on the gastric mucosa (mucus absent) $S E M \times 8750$ (Bar=1 um).

\section{Discussion}

Our findings are in broad agreement with those of previous recent reports, ${ }^{2-7}$ in which the incidence of gastric campylobacter like organisms cultured or observed histologically ranges from $42 \%$ to $64 \%$ in patients referred for upper gastrointestinal endoscopy. The correlation of organisms with biopsy evidence of gastritis is higher ranging from $56 \%$ to $97 \%$. In this study the organism was cultured from $29(57 \%)$ of the 51 patients and from 27 of the 38 $(71 \%)$ biopsies with gastritis. With the successful culture of $C$ pyloridis achieved by western Australian microbiologists ${ }^{3}$ but only towards the end of their study ${ }^{4}$ less reliance need now be placed on the Warthin-Starry stain which is not specific for campylobacter like organisms and depends on assessing bacterial shape by light microscopy (Fig. 1). Despite this theoretical limitation the correlation of positive staining with results of bacterial culture is excellent. ${ }^{5}$ We found full agreement between the two on 45 of the 50 occasions where a confident opinion was possible, furthermore, organisms` were never seen on a normal mucosa.

The current literature, apart from two groups $u 1$ observers, ${ }^{112}$ establishes that $C$ pyloridis seems to survive on only abnormal mucosa. ${ }^{4-7}$ This is usually antral though they have been observed and cultured from the body. ${ }^{1} 1213$ It may be of considerable ecological importance that Phillips and colleagues ${ }^{14}$ in their SEM study also found organisms in the duodenum but only at sites of gastric metaplasia while a corresponding absence has been noted on intestinal metaplastic epithelium in the antrum. ${ }^{13}$ This has also been our experience. ${ }^{15}$ The correlation of culture with mucosal abnormality is remarkable given the patchy nature of gastritis and the limited geograpical sampling of the stomach in this study and the other current publications. ${ }^{2-7}$

If $C$ pyloridis is a cause of gastritis and/or peptic ulceration, a close relationship with inflammatory activity might be expected akin to bacterial disease elsewhere in the intestine. We, like Jones et $a l^{7}$ found no such correlation with 'activity' and even though Marshall and Warren ${ }^{4}$ noted organisms in $38 / 40$ with active gastritis it was also present in $58 \%$ 


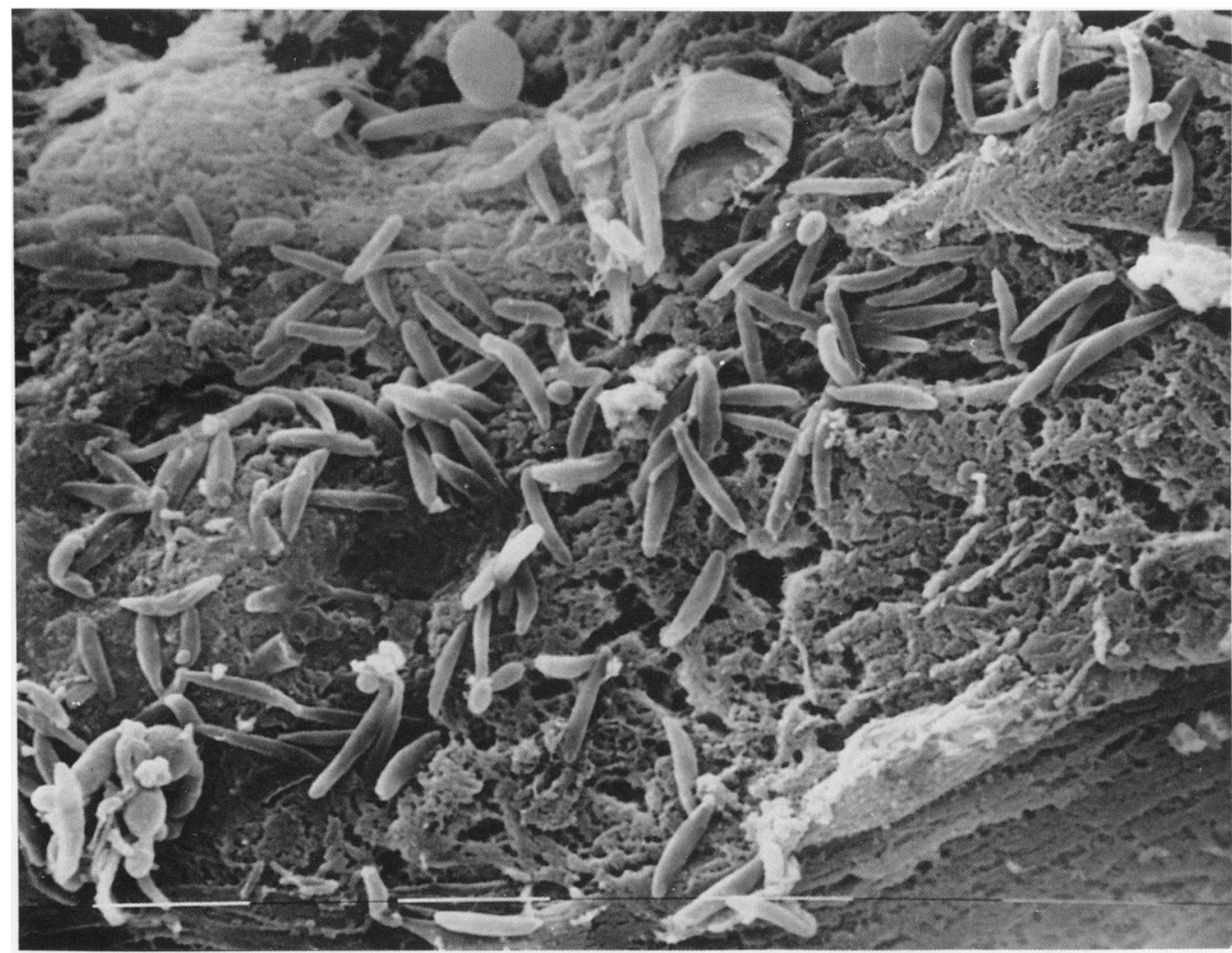

Fig. 3 Unidentified cigar shaped organisms commonly seen in association with $\mathrm{C}$ pyloridis in patients with duodenal ulcers. SEM $\times 2190$ (Bar $=10$ um).

of cases of chronic gastritis their equivalent to our term 'quiescent'. The persistence of $C$ pyloridis despite treatment and ulcer healing, noted in our three patients as well as by others ${ }^{5} 13$ is also against a causal role, though its persistence might be a reason for the recurrent nature of peptic ulcer disease. Our patients were treated with the $\mathrm{H} 2$ receptor antagonists and it is speculated that these preparations while producing rapid healing leave the mucosa susceptible to some ulcerogenic agents and subsequent relapse. ${ }^{16}$ This is in contrast with low relapse rates with some other preparations ${ }^{17}$ which are bactericidal against $C$ pyloridis.

To postulate a role for $C$ pyloridis in peptic ulceration implies that the organism must survive the hostile gastric $\mathrm{pH}$. The SEM findings show they are closely associated with the mucosa (Figs. 1,2) beneath the mucus layer, therefore protected and able to proliferate. The organism was, however, absent in both cases of achlorhydric pernicious anaemia, so that a high $\mathrm{pH}$ of the gastric juice alone does not encourage colonisation. ${ }^{16}$ How they might cause duodenal ulceration is a difficult conceptual problem if their main ecological niche is the gastric antrum and the significance of the larger cigarshaped organisms (Fig. 3) that we observed in conjunction with $C$ pyloridis is also obscure.

Of particular importance in deciding the pathogenecity of $C$ pyloridis will be the outcome in those 'endoscopically normal' from whom it was cultured. It was grown from five of these 14, all of whom had evidence of gastritis in their biopsy, despite normal endoscopy. Langenberg $e t a^{6}$ also found $C$ pyloridis in healthy volunteers. The significance of $C$ pyloridis will be enhanced if on follow up such 'carriers' do indeed develop ulceration. A useful line of investigation in this respect is the serological detection of $C$ pyloridis as demonstrated by Jones et al. ${ }^{7}$ The behaviour of a second patient group will also be of interest, namely those with gastritis and/or ulceration but without $C$ pyloridis present.

The initial data on $C$ pyloridis are exciting. At this early stage its cultural requirements are becoming established as are its associations with gastritis and 
duodenal ulceration. Combining culture results and SEM it was present in 19 of $21(90 \%)$ patients with duodenal ulceration, mainly as the sole organism. At present one might tentatively suggest it is a marker in patients with gastritis at risk of developing a duodenal ulcer. This leaves open the question whether pathogen or opportunist and whether to relocate the chapters on peptic ulcer disease alongside those of infection!

We would like to thank Mr Tsohas and Mrs Smith for their help.

\section{References}

1 Rollason TP, Stone J, Rhodes JM. Spiral organisms in endoscopic biopsies of the human stomach. J Clin Pathol 1984; 37: 23-26.

2 Warren JR, Marshall BJ. Unidentified curved bacilli on gastric epithelium in active chronic gastritis. Lancet 1983; 1: 1273-5.

3 Marshall BJ, Royce H, Annear DI et al. Original isolation of Campylobacter pyloridis from human gastric mucosa. Microbios 1984; 25: 83-88.

4 Marshall BJ, Warren JR. Unidentified curved bacilli in the stomach of patients with gastritis and peptic ulceration. Lancet 1984; 1: 1311-4.

5 McNulty CAM, Watson DM. Spiral bacteria of the gastric antrum. Lancet 1984; 1: 1068-9.

6 Lagenberg ML, Tytgat GNJ, Schipper MEI, Rietra PJGM, Zanen HC. Campylobacter-like organisms in the stomach of patients and healthy individuals. Lancet 1984; $1: 348$.

7 Jones DM, Lessells AM, Eldridge J. Campylobacterlike organisms on the gastric mucosa: culture, histo- logical and serological studies. J Clin Pathol 1984; 37: $1002-6$.

8 Skirrow MB. Taxonomy and biotyping: Morphological aspects. In: Pearson AD, Skjurrow MB, Rowe $B$, Davies JR, Jones DM, eds. Campylobacter II: Proceedings of the Second International Workshop on Campylobacter Infections. London: Public Health Laboratory Service, 1983: 36.

9 Whitehead R. Mucosal biopsy of the gastrointestinal tract. In: Bennington JL, ed. Major problems in pathology: vol. III, 2nd ed. Philadelphia: WB Saunders, 1979: 15

10 Cotton PB, Price AB, Tighe JR, Beales JSM. Preliminary evaluation of 'duodenitis' by endoscopy and biopsy. Br Med J 1973; 3: 430-3.

11 Price AB, Dolby JM, Dunscombe PR, Stirling J. Detection of campylobacter by immunofluorescence in stools and rectal biopsies of patients with diarrhoea. $J$ Clin Pathol 1984; 37: 1007-13.

12 Forrest JAH, Fricker CR, Girdwood RWA, Burnett RA, McDonald JB. Campylobacter-like organisms in mucosa of patients undergoing routine upper gastrointestinal endoscopy. [Abstract]. Gut 1984; 25: A1137.

13 Thomas JM, Poynter D, Gooding C et al. Gastric spiral bacteria. Lancet 1984; 2: 100.

14 Phillips AD, Hine KR, Holmes GKT, Wooding DF Gastric spiral bacteria. Lancet 1984; 2: 100-1.

15 Price AB, Smith A, Dolby J, Clark J, Dunscombe P, Stephenson M, Tsohas-Thomas W. Gastritis, peptic ulcer and C. pyloridis. [Abstract]. J Pathol 1985; 145: 88A.

16 McLean AJ, Harrison PM, Ionannides-Demos LL, Byrne AJ, McCarthy P, Dudley FJ. Microbes, peptic ulcer and relapse rates with different drugs. Lancet $1984 ; 2$ : 525-6.

17 Martin DF, May SJ, Tweedle DEF, Hollanders D, Ravenscroft MM, Miller JP. Difference in relapse rates of duodenal ulcer after healing with cimetidine or tripotassium dicitrate bismuthate. Lancet 1981; 1: 7-12. 